\title{
Systematic virtual screening in search of SARS CoV-2 inhibitors against spike glycoprotein: pharmacophore screening, molecular docking, ADMET analysis and MD simulations
}

\author{
Tejas M. Dhameliya ${ }^{1}$ D . Prinsa R. Nagar ${ }^{1}$ - Normi D. Gajjar ${ }^{1}$ \\ Received: 8 July 2021 / Accepted: 22 January 2022 / Published online: 8 February 2022 \\ (c) The Author(s), under exclusive licence to Springer Nature Switzerland AG 2022
}

\begin{abstract}
In the absence of efficient anti-viral medications, the coronavirus disease 2019 (COVID-19), stemming from severe acute respiratory syndrome coronavirus-2 (SARS CoV-2), has spawned a worldwide catastrophe and global emergency. Amidst several anti-viral targets of COVID-19, spike glycoprotein has been recognized as an essential target for the viral entry into the host cell. In the search of effective SARS CoV-2 inhibitors acting against spike glycoprotein, the virtual screening of 175,851 ligands from the 2020.1 Asinex BioDesign library has been performed using in silico tools like SiteMap analysis, pharmacophore-based screening, molecular docking using different levels of precision, such as high throughput virtual screening, standard precision and extra precision, followed by absorption, distribution, metabolism, excretion and toxicity analysis, and molecular dynamics (MD) simulation. Following a molecular docking study, seventeen molecules (with a docking score of less than -6.0) were identified having the substantial interactions with the catalytic amino acid and nucleic acid residues of spike glycoprotein at the binding site. In investigations using MD simulations for $10 \mathrm{~ns}$, the hit molecules (1 and 2) showed adequate compactness and uniqueness, as well as satisfactory stability. These computational research findings have offered a key starting point in the field of design and development of novel SARS CoV-2 entry inhibitors with appropriate drug likeliness.
\end{abstract}

Tejas M. Dhameliya

tejas.dhameliya@1mcp.ac.in; tmdhameliya@gmail.com

1 L. M. College of Pharmacy, Navrangpura, Ahmedabad, Gujarat 380009, India 


\section{Graphical abstract}

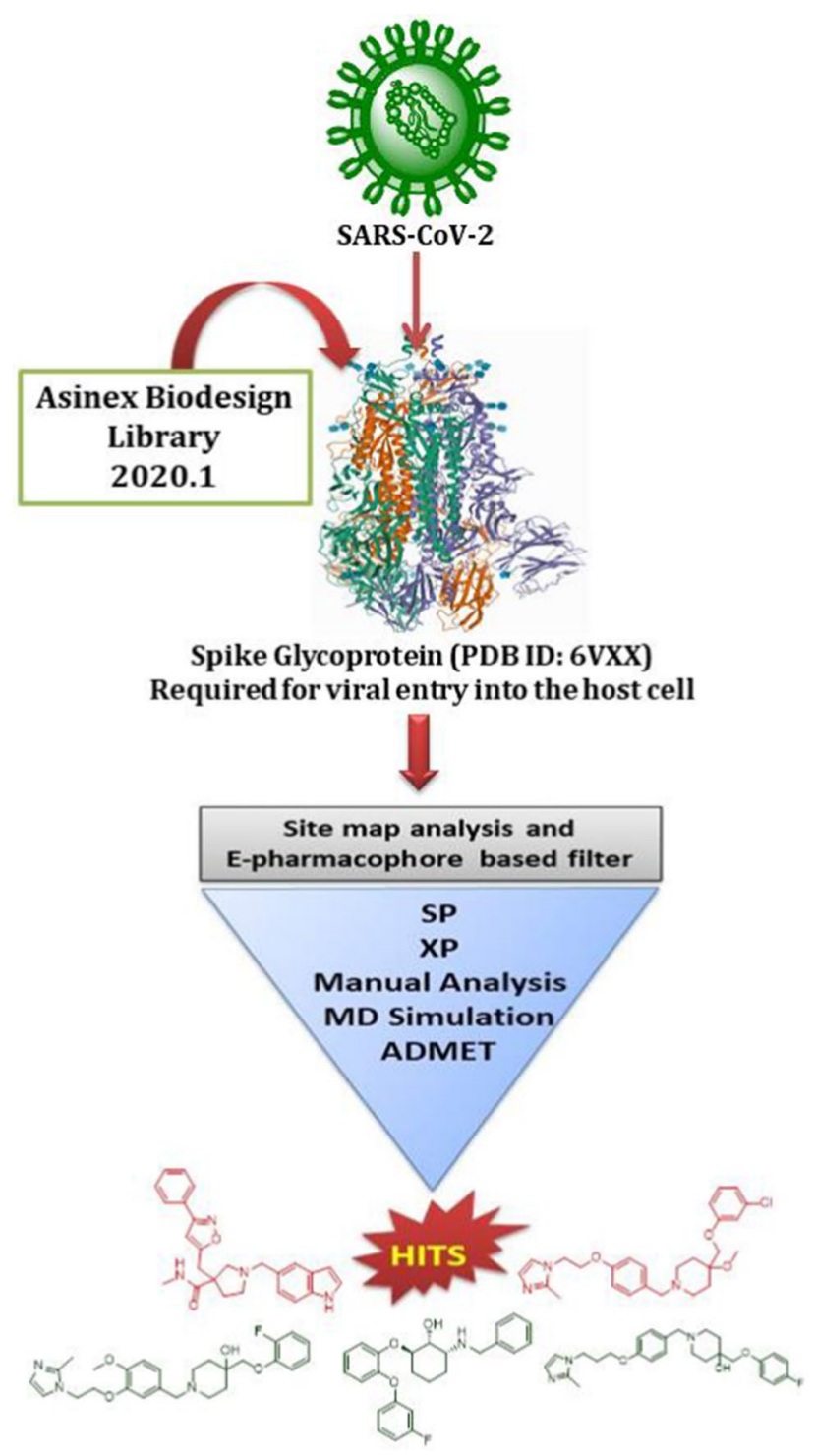

Keywords COVID-19 $\cdot$ SARS CoV-2 $\cdot$ Molecular docking $\cdot$ MD simulations $\cdot$ Spike glycoprotein

\section{Abbreviations}

ACE2

ADMET

ASL

BBB

COVID-19

$\mathrm{E}$

FDA

GLIDE

HBA

HBD
Angiotensin-converting enzyme 2 Absorption, distribution, metabolism, excretion and toxicity

Atom specification language

Blood brain barrier

Coronavirus disease 2019

Envelope protein

Food and drugs administration

Grid-based ligand docking with energetics

Hydrogen bond acceptor

Hydrogen bond donor
HERG Human ether-a-go-go-related gene

HOA Human oral absorption

HTVS High-throughput virtual screening

M Membrane protein

$\mathrm{N} \quad$ Nucleocapsid

$n$ CoV-19 Novel coronaviruses

NSPs Non-structural proteins

OPLS3e Optimized potentials for liquid simulations

$\mathrm{pp} 1 \mathrm{a} / \mathrm{b} \quad$ Polyproteins

RdRp RNA-dependent RNA polymerase

$S$

Spike glycoprotein 
SARS CoV-2 Severe acute respiratory syndrome coronavirus-2

\section{SP Standard precision}

ssRNA Single-stranded ribonucleic acid

TMPRSS2 Transmembrane protease serine type 2

UTR Untranslated region

XP Extra precision

\section{Introduction}

The novel coronavirus disease 2019 (COVID-19), caused by deadly, pathogenic and infectious novel coronaviruses (nCoV-19), has caused an unprecedented pandemic worldwide due to increased virulence, morbidity and rapid spread beyond the previous severe acute respiratory syndrome (SARS) pandemic of 2002-03 [1, 2]. The very first outbreak was reported on December 31, 2019, and suspected to be assembled in the laboratory of Wuhan, China [3-6]. Citing the exceedingly concerning situation, COVID-19 has been designated as an emergency and a worldwide pandemic by the World Health Organization (WHO) on March 11, 2020 [7]. According to the latest WHO estimates, there were $326,279,424$ confirmed cases of COVID-19 worldwide as of January 17, 2022, with 5,536,609 fatalities [8]. The severe effects of quarantine-related counter-measures imposed by ruling governments, such as lock-down, sanitization of public premises, social distancing, closure of academies or sports clubs, cancellation of public or social events, etc., have severely hampered normal life around the world. As a result, the socioeconomic consequences of the epidemic have steadily damaged societal health, education, economy and several vital sectors have been greatly challenged or ceased $[9,10]$.

Coronaviruses (CoVs) are single-strand positive-sense RNA enclosed viruses that belong to a large family [11]. Being club-shaped glycoprotein, they are around 60-140 nm in diameter with the crown-like morphology of the virion as observed using electron microscopy [12, 13]. The first strain of SARS coronavirus species was identified in 2002-3 [14]. As a spillover disease, it has spread throughout the world through a variety of hosts, including bats, civets, camels, and among others $[15,16]$. The huge subfamily of CoVs belongs to the Nidovirales family, divided further into four primary genuses: alpha, beta, gamma and delta-coronaviruses, among which SARS CoV- 2 belongs to $\beta$-coronaviruses [4, 17]. Patients with the condition may experience a variety of clinical manifestations, ranging from minor to severe symptoms such as headaches, shortness of breath, muscular pains, fever and tiredness, to multi-organ failure $[18,19]$. Inhalation of respiratory droplets, usage of personal belongings of the infected patients, direct or indirect physical exposure and contamination have been regarded as the ways for the illness to spread among human beings [20].

Despite the devastating effects, no viable medicines to tackle COVID-19 have been identified so far. There are currently sixty-three diversified vaccines containing inactivated viruses (Covaxin), adeno-based vaccines (Gam-Covid by Gameleya Institute), recombinant (Novavax), mRNA (Moderna) and live attenuated vaccines that have been approved on a global basis by regulatory authorities in order to effectively diminish or uproot the effect of COVID-19. More than twenty vaccinations are in phase III clinical investigations and will be introduced with better efficacy and safety in the future. However, repurposing of existing anti-viral drugs and development of vaccines could not act straightforwardly proving themselves an effective therapy to prevent the virus for making its way to animal species through binding with spike glycoprotein. Additionally, they bring noticeable ill effects on the imperative physiological processes of human body upon administration such as revering to the deficit of potential therapy in this line of approach; there is an urgent need for the development of promising candidates [21, 22].

To become an FDA-approved drug, the molecules must have to pass through the hectic discovery process through conventional methods at the cost of billions of US dollars that too might not guarantee a potential therapy. On the other hand, drug discovery through the cost effective virtual screenings could serve the purpose of novel drug discovery for the eradication of SARS CoV-2 proving itself a need of an hour [22-25]. In order to get an effective therapeutic approach, critical insights into the viral entry and replication cycle into host's body have been urged to understand the pathogenesis of SARS CoV-2 (Fig. 1). The viral replication process starts with the entry of virion into host cells via spike glycoprotein (S), which is followed by the use of host cell machinery to assemble and reproduce multiple viral parasites. Spike protein, which is made up of two essential subunits called S1 and S2, facilitates in virus binding and fusion to the host cell membrane, which is accomplished via endocytosis or cleavage at the interface of the two subunits by host proteases such as transmembrane protease serine type 2 (TMPRSS2) and cathepsin. Furthermore, the released $30 \mathrm{~kb}$ positive-sense single-stranded ssRNA (5'-3' UTR) into the host cytoplasm uses host cell machinery to translate into polyproteins, which are then proteolytically cleaved into sixteen distinct non-structural proteins by the proteases encoded by the virus (NSPs). These NSPs construct a replicase-transcriptase complex, which incorporates RNA-dependent RNA polymerase (RdRp), helicases, endo and exonucleases, and other important enzymes involved in nucleic acid metabolism. Open reading frames required for transcription into structural proteins such as spike (S), membrane $(\mathrm{M})$, nucleocapsid $(\mathrm{N})$ and envelope $(\mathrm{E})$ are encoded at the 3 '-end of the genome (E). The proteins generated in the 


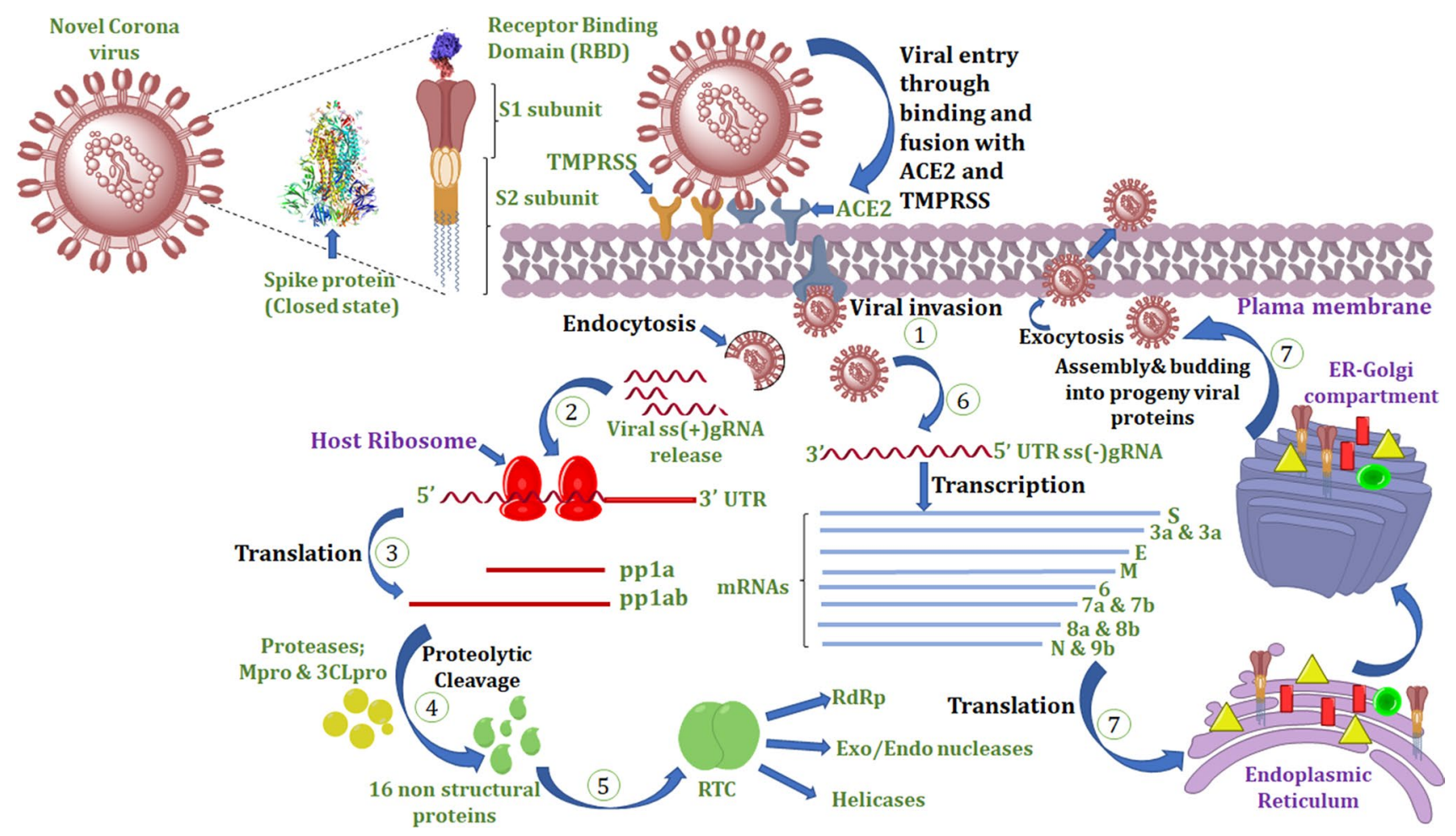

Fig. 1 Life cycle of SARS CoV-2 from entry to replication into host cells<smiles>Cc1cc(-c2ccc(N=Nc3ccc4c([N+](=O)[O-])cc(S(=O)(=O)O[Na])c(N)c4c3O)c(C)c2)ccc1N=Nc1ccc2c(OS(=O)(=O)O)cc(S(=O)(=O)O[Na])c(N)c2c1O</smiles>

Fig. 2 Reported spike-ACE2 inhibitors inhibiting SARS CoV-2 attachments and their entries in host cells

endoplasmic reticulum (ER) of the host cell are transformed into new viral offspring, which are then released into ERgolgi compartments and infect additional host cells [26, 27] .

In search of SARS CoV-2 inhibitors, Buchwald and coworkers have performed the virtual screening of library consisting of organic dyes and reported $p$-nitrobenzamide derivative (A, Fig. 2) with the $\mathrm{IC}_{50}$ of $5.6 \mu \mathrm{M}$, as spikeACE2 protein-protein interaction blockers inhibiting the attachment and entry of coronavirus to human cells [28]. The multidisciplinary approach performed by Haselhorst et al. via screening of 57,641 ligands to inhibit human ACE2 or spike protein led to identification of evans blue (B, Fig. 2) as potent anti-viral agent with $\mathrm{IC}_{50}$ of $28.1 \mu \mathrm{M}$ against veroE6 cells incubated with SARS CoV-2 [29]. Three different peptide fragments composed of $N$-terminal amino acid residues of $\alpha_{1}$ helix of ACE2 peptidase domain have been reported by de Olivera and co-workers as effective agents to inhibit the binding of SARS CoV-2 spike protein with human ACE2 as identified through molecular modelling [30]. Further, Baig et al. identified the 13-amino acid peptide (FLDKFNHEAEDLF) as spike protein inhibitor with minimal inhibition ( $40 \%$ at $100 \mu \mathrm{M}$ concentration) of ACE2spike protein-protein interactions through enzyme-linked immunosorbent (ELISA)-dependent inhibitory assay [31].

The use of computational studies has promoted the design and discovery of new chemicals scaffolds acting against the choice of drug targets through molecular modelling techniques like molecular docking, ADMET analysis and molecular dynamics (MD) simulation [32]. Recently, we have reported the virtual screening of small molecules against RdRp [33] and Mpro [34] using molecular docking, ADMET analysis and MD simulations. In continuation towards our endeavour for search of SARS CoV-2 inhibitors, we become interested for the in silico-based virtual screening of 175,851 ligands of Asinex BioDesign library 
considering the massive demand for SARS CoV-2 inhibitors having good binding affinity towards the spike glycoprotein.

\section{Results and discussion}

\section{Pharmacophore hypothesis}

\section{SiteMap analysis}

The protein structure of spike protein (PDB ID: 6VXX) having resolution of $2.8 \AA$ with the symmetrical trimeric structure possessing two receptor binding domains (S1 and S2 domains) has been deposited in protein data bank by Veesler et al. [35]. There has not been any ligand co-crystallized with the protein of interest. As a result, attempts have been made to determine the probable binding site of spike glycoprotein using the SiteMap tool of Schrödinger [36]. Five possible active sites have been predicted, and their drugability scores (Dscore) and SiteScores have been calculated by consideration of the pocket volume, enclosure, and the degree of hydrophobicity (Table 1) [37]. Next, the site having the highest Dscore (1.103642) has been utilized for the pharmacophore hypothesis development which includes residues Lys41, Ile197, Asp198, Tyr200, Lys202, Asp228, Arg355, Cys379, Tyr380, Gly381, Val382, Ser383, Tyr396, Ala411, Pro412, Gly413, Gln414, Thr415, Ala419, Asp420, Lys424, Pro426, Asp427, Asp428, Phe429, Thr430, Phe464, Ser514, Phe515, Glu516, Leu517, Leu518, His519, Glu748, Asn751, Leu752, Gln755, Tyr756, Gln762, Leu763, Arg765, Ala766, Gly769, Ile770, Glu773, Val951, Gln954, Gln957, Ala958, Thr961, Leu962, Gln965, Phe970, Gly971, Ile973, Ser974, Asp979, Leu981, Arg983, Leu984, Asp985, Pro986, Pro987, Glu988, Ala989, Glu990, Va1991, Gln992, Asp994, Arg995, Thr998, Gly999, Leu1001, Gln1002, Ser1003, Gln1005, Thr1006, Tyr1007, Val1008, Thr1009, Gln1010, Gln1011, Leu1012, Ile1013, Arg1014, Ala1015, Ala1016, Glu1017, Ile1018 and Arg1019 (Table 1, Entry 1).

\section{Pharmacophore development and ligand screening}

Next, using the phase module of Schrödinger, an energybased pharmacophore (e-pharmacophore) hypothesis model has been generated around the predicted binding site of spike

Table 1 Predicted five sites from the sitemap analysis for the selected spike protein (PDB ID: 6VXX)

\begin{tabular}{lll}
\hline Entry & SiteScore & Dscore \\
\hline 1 & 1.069965 & 1.103642 \\
2 & 1.054111 & 1.057707 \\
3 & 1.035711 & 1.025884 \\
4 & 1.128571 & 1.011641 \\
5 & 1.027926 & 0.997882 \\
\hline
\end{tabular}

glycoprotein to obtain the steric and electrostatic attributes [38]. The model with seven features (RRRRRRH) has been generated comprising of six aromatic rings $(\mathrm{R})$ and a hydrophobic feature (H, see supporting information, Fig. S2). Total 175,851 numbers of compounds have been obtained from Asinex BioDesign library 2020.1 from online available sources [39]. With a view of validation of the developed hypothesis, all the compounds have been processed through preparation of ligands using LigPrep [40] followed by screening using phase [38]. Total 38,267 molecules from the selected database have matched with the minimum four features of the developed hypothesis, and they have been further utilized for the molecular docking.

\section{Molecular docking}

Molecular modelling using docking [41-44] has been considered as an important computational tool to predict the binding interactions of the ligands with the active site of protein in search of their mode of action against SARS CoV-2 [45-52]. In this context, we have performed the molecular docking in the search of potent SARS CoV-2 inhibitors using the obtained hypothesis model. The receptor grid box with $10 \AA$ has been generated to perform the molecular docking on the selected active site from the SiteMap analysis using the Grid-based Ligand Docking with Energetics (GLIDE) module of Schrödinger [53]. To get the detailed knowledge about the binding strength and types of interactions of the ligand with receptor, we have performed sequential docking at three different precision levels such as high throughput virtual screening (HTVS), standard precision (SP) and extra precision (XP). First of all, the HTVS has been performed using 38,267 ligands, qualified in phase screening, from which 1094 molecules have been found with the docking score of $\leq-4.6$. Next, they have been further processed for docking with SP mode and 175 molecules have been identified with the docking score $\leq-5.9$ in SP docking which have been passed through the XP docking with the generation of 10 poses for each ligand molecule. From that, seventeen compounds with highest docking scores $(\leq-6.0)$ have been identified and summarized in Table 2, and 2-D interactions are presented in Figs. 3, 4 and 5.

Further, we have studied the detailed 3D interactions of the docked ligands having the docking score $\leq-6.0$ using the PyMol 2.4.0 [54]. Compound 1 has shown the highest docking score of -7.34 by formation of the hydrogen bond (HB) interactions with Phe970 and Asp994 along with the two salt bridges with Asp994 as presented in Fig. 6a. Hydroxy group and nitrogen atoms were involved in the bond formation. The nitrogen atom present in the five membered ring of compound $\mathbf{2}$ has interacted with Arg995 through $\pi$-cation interaction and ionic interactions (salt bridge) with Asp994 (Fig. 6b). Another 
Table 2 Molecular docking result of identified hits with the docking score $\leq 6$ in $\mathrm{XP}$

\begin{tabular}{|c|c|c|c|c|}
\hline $\begin{array}{c}\text { Compd. } \\
\text { No. }\end{array}$ & Dataset ID & 2D-Structures & $\begin{array}{c}\text { Docking } \\
\text { Scores }\end{array}$ & $\begin{array}{c}\mathrm{G} \\
\text { score }\end{array}$ \\
\hline 1 & $\begin{array}{c}\text { LAS } \\
52153344\end{array}$ & & -7.34 & -7.43 \\
\hline 2 & $\begin{array}{c}\text { LAS } \\
52165865\end{array}$ & & -7.25 & -7.34 \\
\hline 3 & $\begin{array}{c}\text { LAS } \\
33586443\end{array}$ & & -7.09 & -7.09 \\
\hline 4 & $\begin{array}{c}\text { BDE } \\
33953587\end{array}$ & & -6.78 & -6.86 \\
\hline 5 & $\begin{array}{c}\text { BDD } \\
27849696\end{array}$ & & -6.77 & -6.88 \\
\hline 6 & $\begin{array}{c}\text { BDE } \\
19706336\end{array}$ & & -6.63 & -6.64 \\
\hline 7 & $\begin{array}{c}\text { LAS } \\
52167276\end{array}$ & & -6.62 & -6.93 \\
\hline 8 & $\begin{array}{c}\text { BDE } \\
19706291\end{array}$ & & -6.54 & -6.55 \\
\hline 9 & $\begin{array}{c}\text { BDF } \\
26908734\end{array}$ & & -6.53 & -6.54 \\
\hline 10 & $\begin{array}{c}\text { LAS } \\
52164699\end{array}$ & & -6.50 & -6.63 \\
\hline 11 & $\begin{array}{c}\text { LAS } \\
52126337\end{array}$ & & -6.48 & -7.52 \\
\hline 12 & $\begin{array}{c}\text { LAS } \\
52160955\end{array}$ & & -6.33 & -6.35 \\
\hline 13 & $\begin{array}{c}\text { LAS } \\
52154116\end{array}$ & & -6.23 & -6.37 \\
\hline
\end{tabular}


Table 2 (continued)

$\begin{array}{cccc}\begin{array}{c}\text { Compd. } \\ \text { No. }\end{array} \text { Dataset ID } & \begin{array}{c}\text { Docking } \\ \text { Scores }\end{array} & \begin{array}{c}\text { G } \\ \text { score }\end{array} \\ 14 & & & \end{array}$

(1)

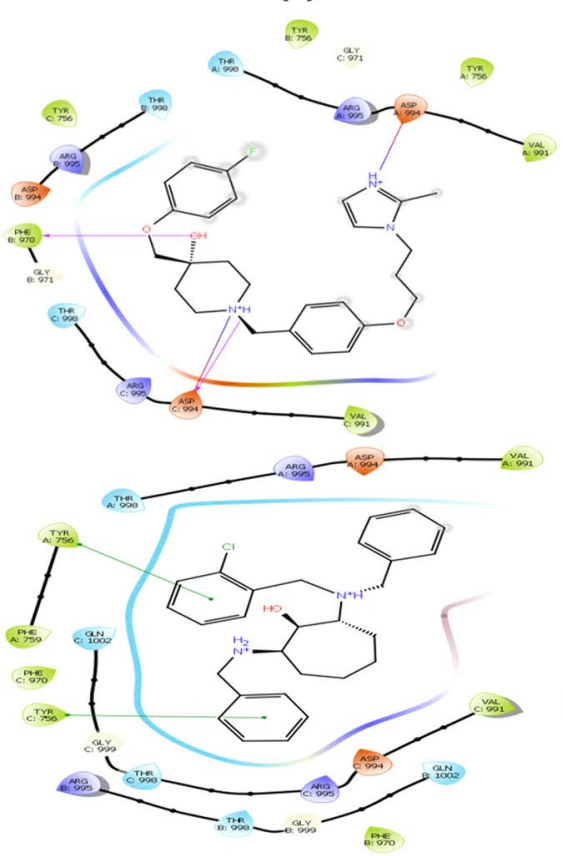

(4)

(2)

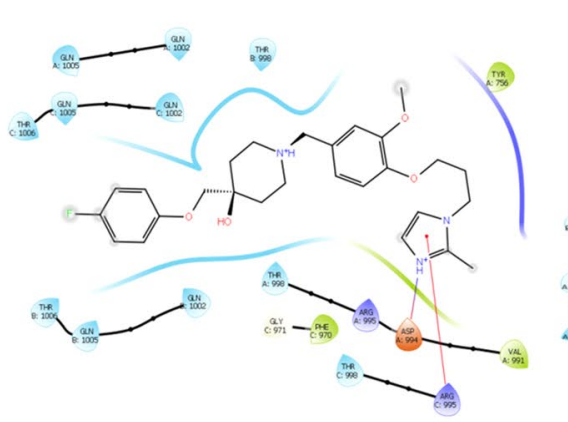

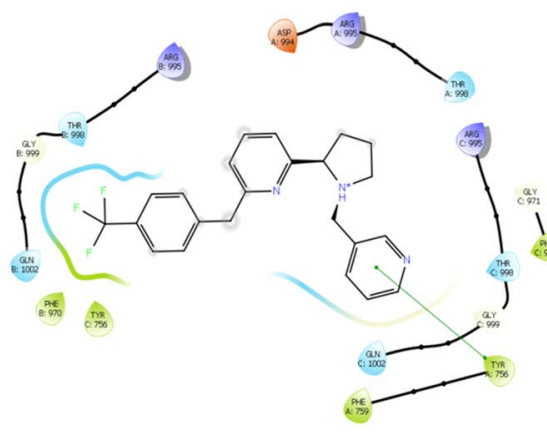

(5)
(3)

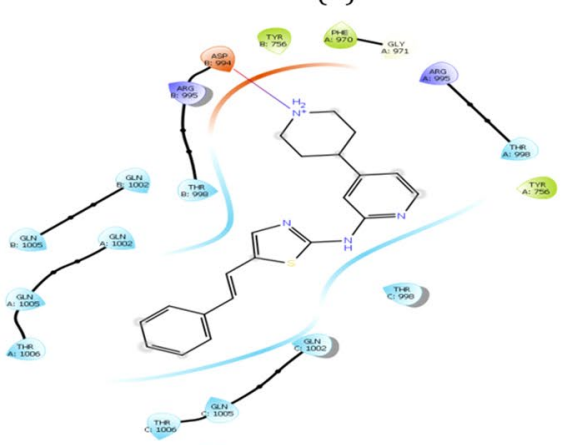

Fig. $32 \mathrm{D}$ interactions of compounds having docking score of $\leq-6.0$ using XP module against spike glycoprotein. HB has been represented as purple-coloured arrows and $\pi-\pi$ bond as green lines; solvent exposures have been presented through grey spot and salt bridge as red-blue lines

compound $\mathbf{3}$ has also shown the similar interactions with Asp994 residue via formation of salt bridge with nitrogen atom (Fig. 6c) being tight binding in the predicted active site of spike glycoprotein. Benzene rings of compound $\mathbf{4}$ (Fig. 6d) and nitrogen atom present in the benzene ring of 5 (Fig. 6e) have been found to form double and single and 
(7)

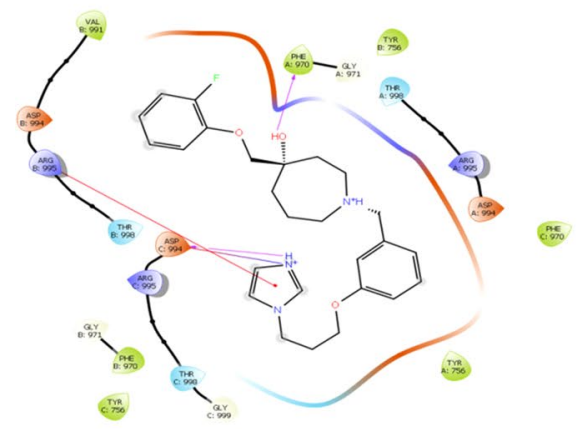

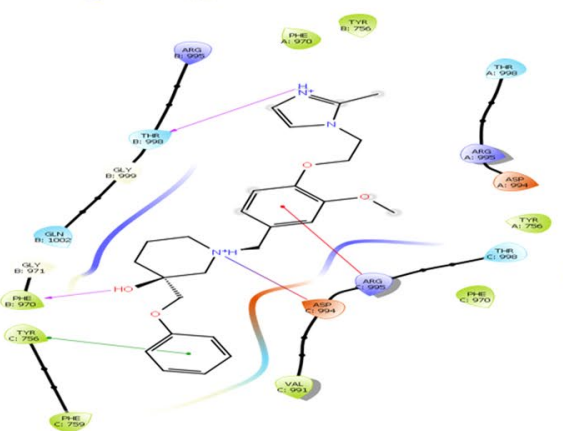

(10)
(8)
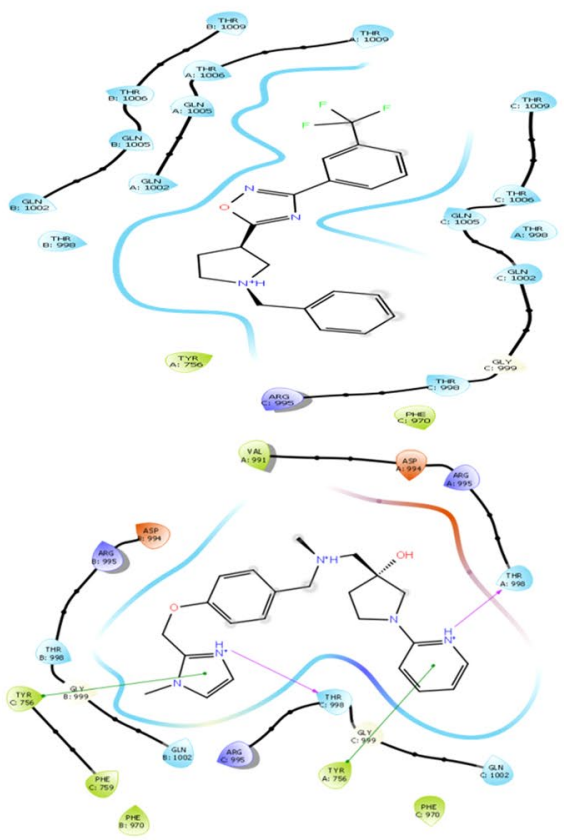

(11)
(9)
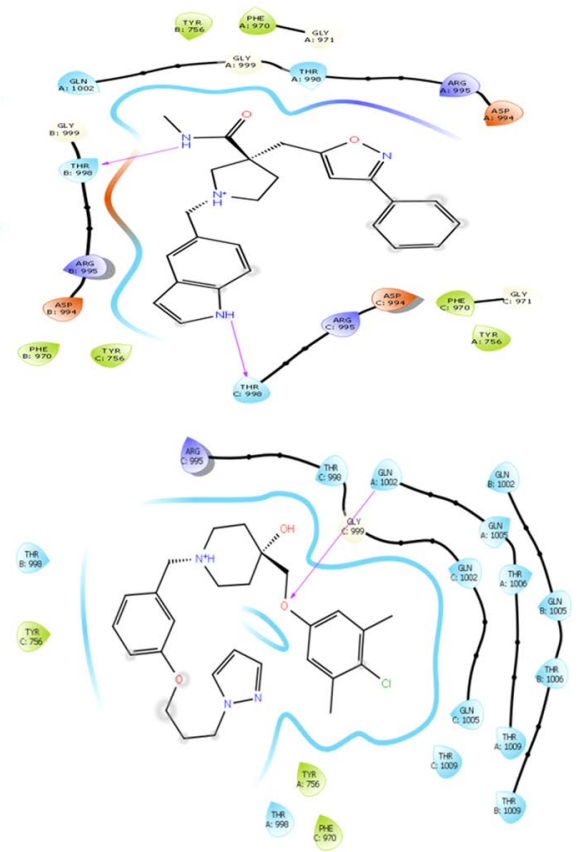

(12)

Fig. 4 2D interactions of compounds having docking score of $\leq-6.0$ using XP module against spike glycoprotein. HB has been represented as purple-coloured arrows and $\pi-\pi$ bond as green lines; solvent exposures have been presented through grey spot and salt bridge as red-blue lines

(13)

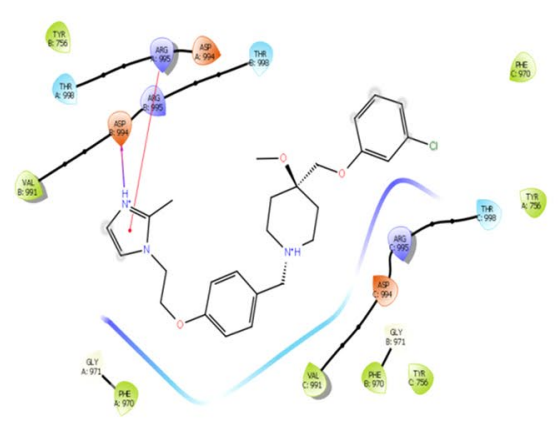

(14)

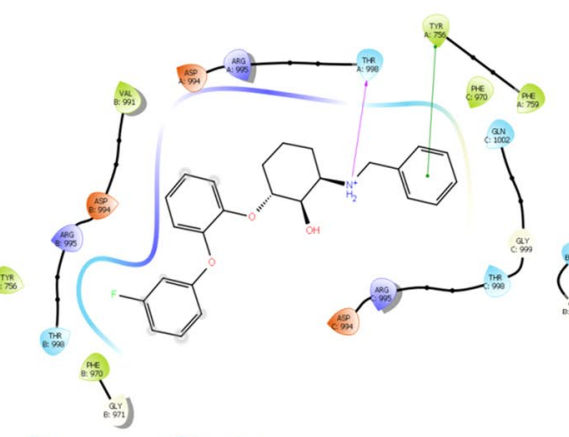

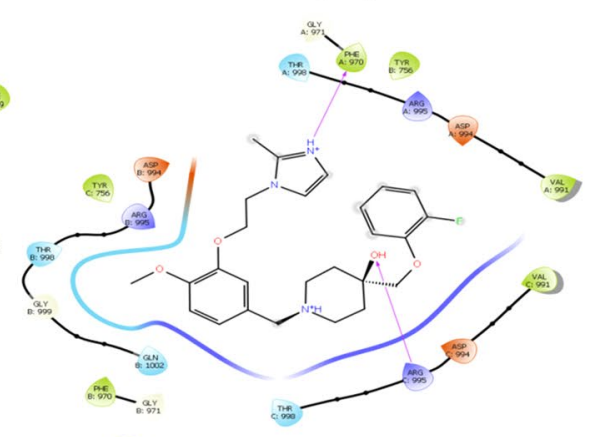

(15)

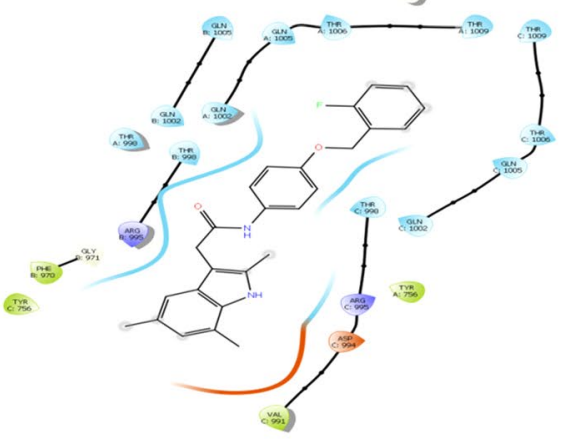

(16)

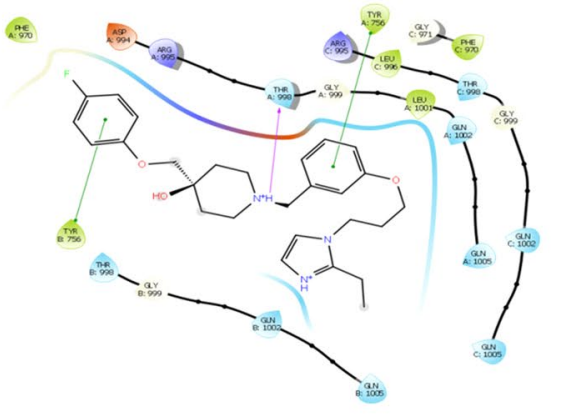

(17)

Fig. $52 \mathrm{D}$ interactions of compounds having docking score of $\leq-6.0$ using XP module against spike glycoprotein. HB has been represented as purple-coloured arrows and $\pi-\pi$ bond as green lines; solvent exposures have been presented through grey spot and salt bridge as red-blue lines 

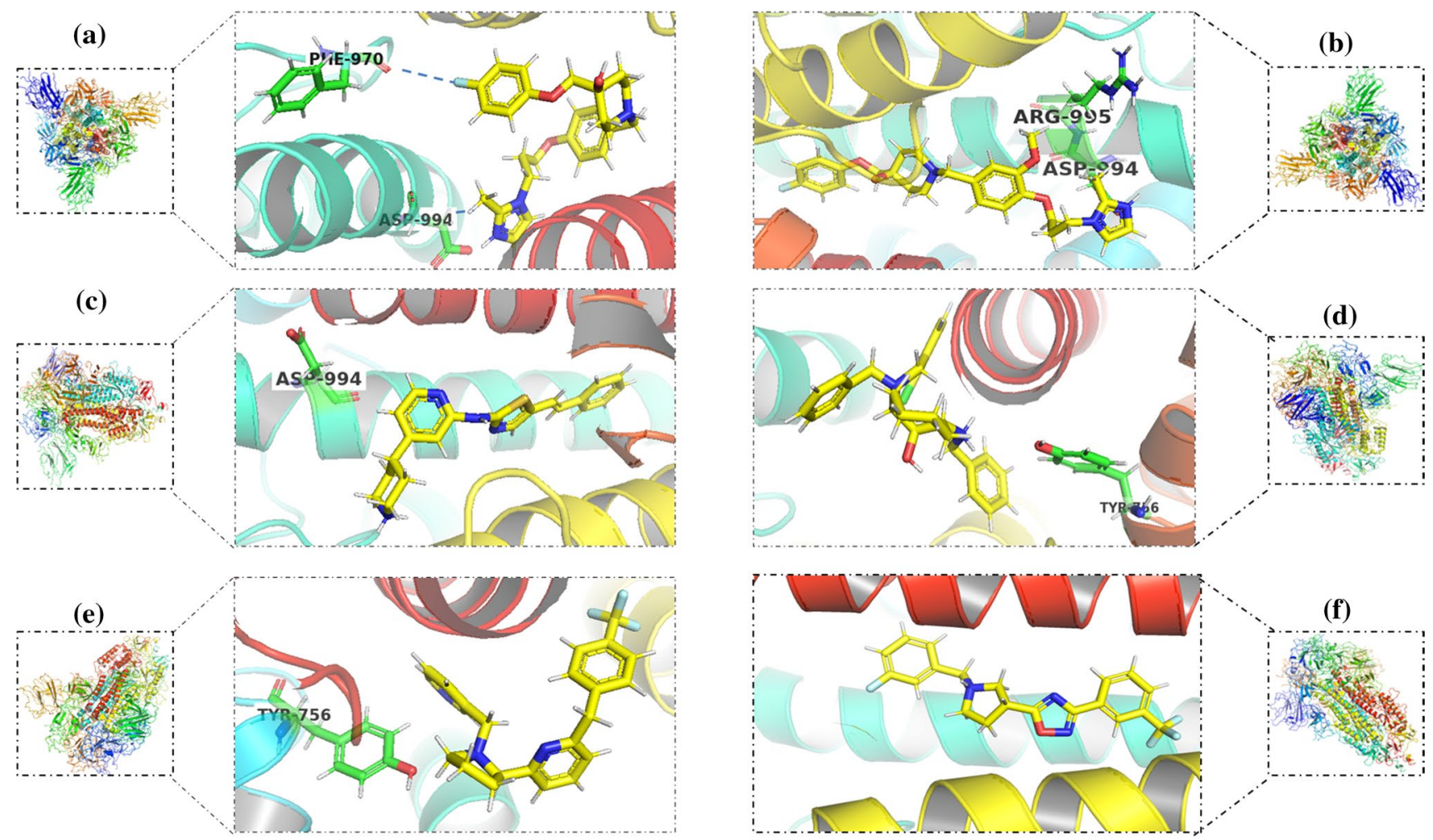

Fig. 6 3D interactions of identified hits including $1(\mathbf{a}), \mathbf{2}(\mathbf{b}), \mathbf{3}(\mathbf{c}), \mathbf{4}(\mathbf{d}), \mathbf{5}(\mathbf{e})$ and $\mathbf{6}(\mathbf{f})$ through XP docking. The poses for the represented ligands (yellow coloured ball and stick models) and protein (coloured cartoons) have been generated and visualized using PyMol 2.4.1 [54]

$\pi-\pi$ interactions, respectively, with Tyr756. Additionally, compound 6 has been fitted in the active site with maximum exposures to solvent molecules specifically with the fluorine atom (Fig. 6f).

Hydroxy and amine group of $1 H$-imidazole derivative (7) has been involved in $\pi$-cation interaction with Arg995 along with the formation of salt bridge (Asp994) and HB (Asp994 and Phe970, Fig. 7a). Biologically divergent 1,2,4-oxadiazole derivative (8) [55] has been tightly accommodated with several solvent molecules and surrounded by amino acid residues in the active site of spike glycoprotein (Fig. 7b). The nitrogen atoms of hybrid heterocyclic scaffold 9 have been found to form HB with Thr998 (Fig. 7c) with docking score of -6.53 (Entry 9, Table 2). Compound $\mathbf{1 0}$ has been found with formation of HB with Thr998 and Thr970, salt bridge with Asp994, $\pi$-cat with Arg995 and $\pi-\pi$ bond with Tyr756 (Fig. 7d) showing the string interactions in the active site of protein. Hydroxy and amine groups were found to involve in the interaction. Pyrimidine derivative compound $\mathbf{1 1}$ has been found to fit into the active site by formation of $\mathrm{HB}$ with Thr998 along with two $\pi-\pi$ bonds with Tyr756 (Fig. 7e). The HB formation has been observed between Gln 1002 and ethereal oxygen (HB acceptor) attached to 4-chlorophenyl ring of compound 12 (Fig. 7f) having docking score of -6.33 (Entry 12, Table 2).
Compound $\mathbf{1 3}$ has been found to form the $\pi$-cation interaction with Arg995 (Fig. 8a) along with formation of salt bridge and HB formation with Asp994 resulting in docking score of -6.23 (Entry 13, Table 2). Nitrogen of the amine group of non-heterocyclic compound $\mathbf{1 4}$ has formed HB with Thr998 residue and $\pi-\pi$ bond interaction with Tyr756 residue (Fig. 8b), whereas nitrogen atom and hydroxy group present in compound $\mathbf{1 5}$ have been found to forms HB with Phe970 and Arg995 residues (Fig. 8c). Synthetically divergent indole [56] compound $\mathbf{1 6}$ has been found in the active site with mainly solvent exposure (Fig. 8d) with the docking score of -6.04 (Entry 16, Table 2). Nitrogen of the amine group present in the 2-ethyl imidazole derivative $\mathbf{1 7}$ has been observed with the formation of HB with Thr998 and $\pi-\pi$ bonds with the Tyr756 residues of both chains A and B (Fig. 8e).

\section{ADMET analysis}

Further, we have performed the analysis of absorption, distribution, metabolism, excretion and toxicity (ADMET) parameters for the identified hits through XP docking using QikProp module of Schrödinger [57]. Various physicochemical properties like molecular weight (MW), oil/water partition coefficient $(\log \mathrm{P})$, water solubility $(\operatorname{LogS}), \mathrm{IC}_{50}$ value 

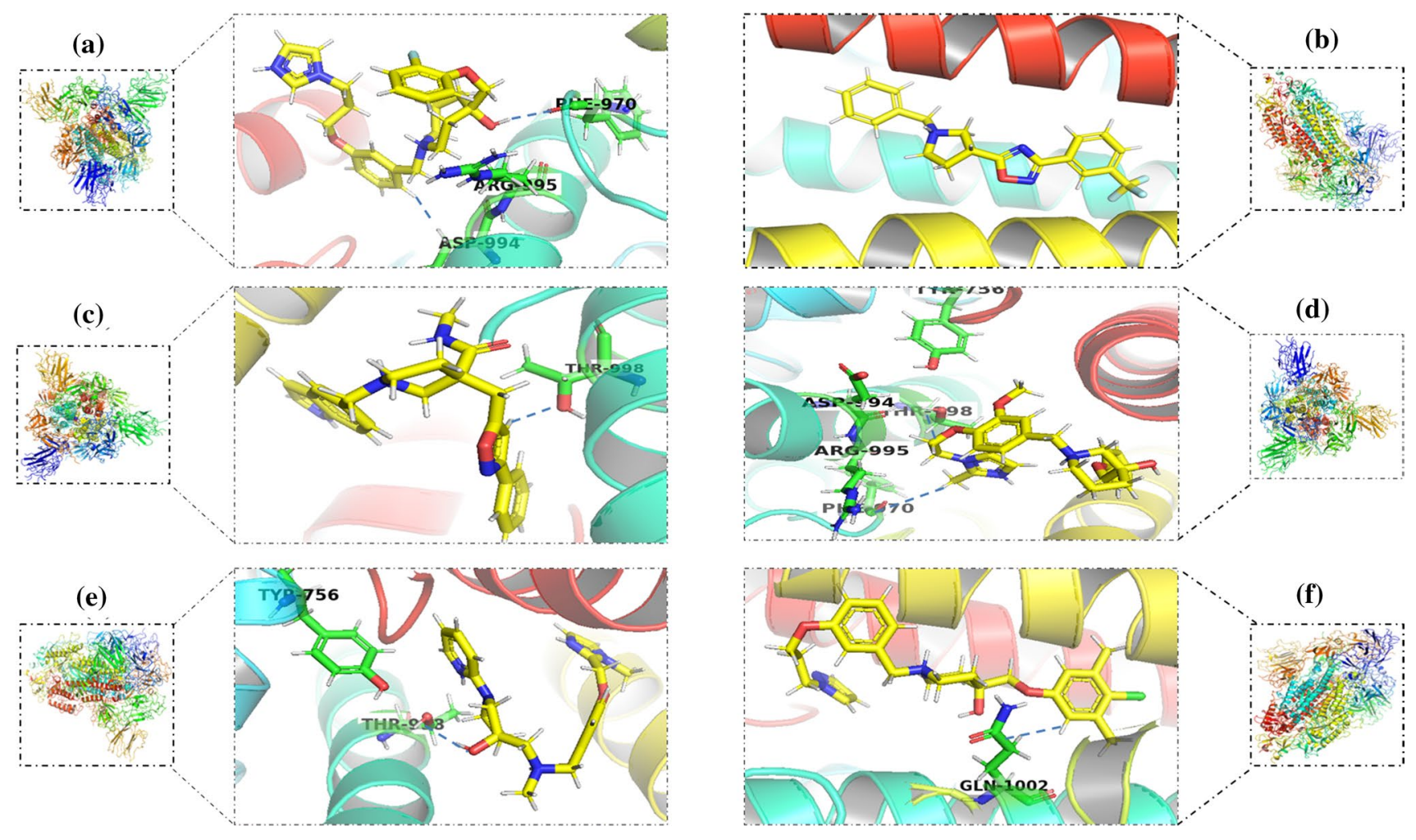

Fig. 7 3D interactions of identified hits including $7(\mathbf{a}), \mathbf{8}(\mathbf{b}), \mathbf{9}(\mathbf{c}), \mathbf{1 0}(\mathbf{d}), \mathbf{1 1}(\mathbf{e})$ and $\mathbf{1 2}(\mathbf{f})$ through XP docking. The poses for the represented ligands (yellow coloured ball and stick models) and protein (coloured cartoons) have been generated and visualized using PyMol 2.4.1 [54]

for blockage of (human ether-a-go-go-related gene (HERG) $\mathrm{K}^{+}$channels, gastrointestinal (GI) cell for cell permeability (QPP caco2), brain/blood partition coefficient (Log BB), number of metabolic reactions (Metab), binding affinity to human serum albumin (QPLog Khsa) and human oral absorption in percentage (\% HOA) have been studied for the selected compounds and are presented in Table 3. Mostly all the hits have satisfied the ADMET criteria, and all the hit molecules may have good oral absorption. This provides better scope for the drug molecule development in the future.

The Lipinski's rule of five (Ro5) has been recognized as the suitable in silico tool for the assessment of essential physico-chemical properties of the hits or leads identified during pre-clinical settings [59]. To ensure the drug likeliness of the hit molecules, the physico-chemical properties for Ro5 have been also evaluated using the QikProp module of Schrödinger [57]. The parameters described under Lipinski's rule of five such as molecular weight (MW), number of hydrogen bond donor (HBD) and acceptor (HBA), oil to water partition coefficient $(\operatorname{LogP})$ and number of rotatable bonds (RB) have been studied (Table 4). The analysis of these properties revealed that none of the hits has violated more than one rule as per the criteria of the Lipinski's Ro5, highlighting the significance of these hits in the search of SARS CoV-2 inhibitors.
The Brain Or IntestinaL EstimateD permeation method (BOILED-Egg) gives the estimation of accessibility of compounds to gastrointestinal (GI) tract and blood-brain barrier [60]. So, we also evaluated the accessibility of the hits using SwissADME [61]. The boiled egg model revealed all the hit molecules possessed satisfactory GI absorption along with inhibition of the P-glycoprotein, a protein responsible for efflux of drugs from cells (Fig. 9). All the compounds (except 3 and 16) may have sufficient permeability across the blood-brain permeability (BBB) indicating their usefulness to treat the infectious disorders related to central nervous system.

The presently identified compounds (1-17) gain the advantage of sufficient metabolic stability and free from nitro-aryl derived toxicity over the literature reported compounds (A and B, Fig. 2), whereas these organic (azo)dyes (A and B) suffer from the limitations of intense colour and metabolic instabilities limiting their therapeutic potential against pathogenic diseases [62]. Further, compound A possesses nitro-aryl features imparting the potential risk of mutagenicity due to interaction of nitro group with DNA [63]. Peptides identified by de Oliveira et al. [30] and Baig et al. [31] may not have sufficient oral bioavailability as compared to identified small molecules (1-17) due to 


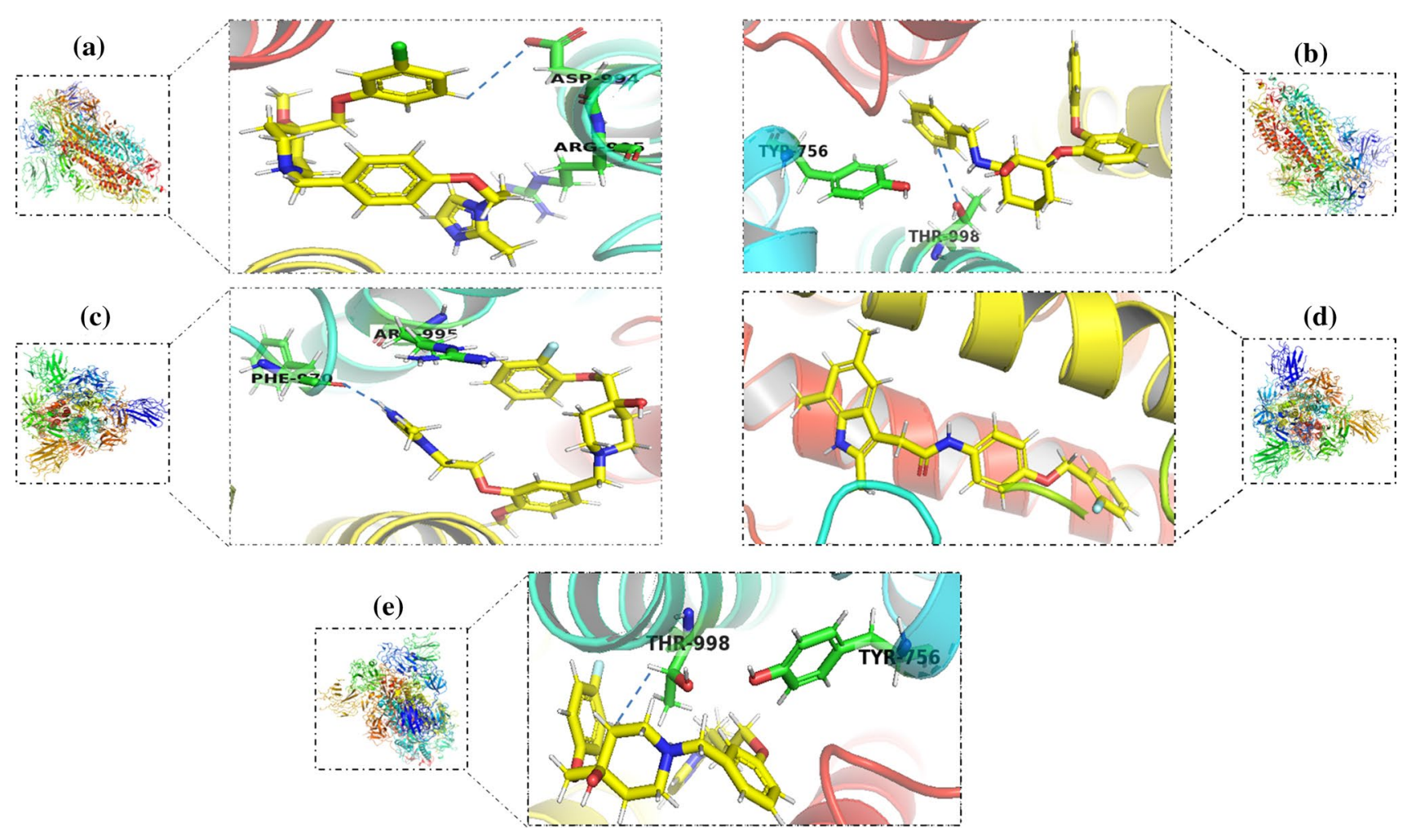

Fig. 8 3D interactions of identified hits including $13(a), 14(\mathbf{b}), 15(\mathbf{c}), \mathbf{1 6}(\mathbf{d})$ and 17 (e), through XP docking. The poses for the represented ligands (yellow coloured ball and stick models) and protein (coloured cartoons) have been generated and visualized using PyMol 2.4.1 [54]

Table 3 ADMET parameters of the identified hits

\begin{tabular}{|c|c|c|c|c|c|c|c|c|c|}
\hline Compd. No & $\mathrm{MW}^{\mathrm{a}}$ & $\log P^{b}$ & $\log S^{c}$ & QPlog HERG $^{\mathrm{d}}$ & QPP $\operatorname{caco}^{\mathrm{e}}$ & $\log B B^{f}$ & Metab $^{g}$ & QPLog Khsa $^{\mathrm{h}}$ & $\% \mathrm{HOA}^{\mathrm{i}}$ \\
\hline 1 & 453.56 & 5.18 & -3.90 & -5.69 & 591.32 & -0.16 & 6 & 0.83 & 93.95 \\
\hline 2 & 483.58 & 5.96 & -6.25 & -7.59 & 760.69 & -0.26 & 7 & 1.03 & 100 \\
\hline 3 & 362.49 & 4.35 & -5.49 & -7.58 & 401.76 & -0.13 & 4 & 0.76 & 100 \\
\hline 4 & 449.03 & 5.06 & -3.73 & -8.30 & 287.78 & 0.54 & 6 & 0.94 & 87.64 \\
\hline 5 & 397.44 & 5.34 & -5.57 & -7.05 & 1267.41 & 0.70 & 6 & 0.85 & 100 \\
\hline 6 & 391.37 & 4.57 & -5.60 & -7.03 & 746.09 & 0.66 & 4 & 0.60 & 100 \\
\hline 7 & 453.56 & 4.77 & -3.58 & -6.41 & 685.05 & -0.18 & 5 & 0.61 & 100 \\
\hline 8 & 373.38 & 3.88 & -4.46 & -6.58 & 524.52 & 0.43 & 4 & 0.41 & 100 \\
\hline 9 & 414.51 & 3.61 & -4.30 & -5.93 & 194.37 & -0.31 & 3 & 0.47 & 89.06 \\
\hline 10 & 451.56 & 5.43 & -4.82 & -6.42 & 682.53 & -0.28 & 7 & 0.97 & 96.48 \\
\hline 11 & 407.51 & 4.59 & -4.54 & -7.04 & 716.06 & -0.09 & 6 & 0.68 & 100 \\
\hline 12 & 484.04 & 6.13 & -6.27 & -7.25 & 918.95 & -0.07 & 7 & 1.14 & 100 \\
\hline 13 & 470.01 & 5.63 & -4.56 & -6.12 & 1244.17 & 0.23 & 5 & 0.80 & 100 \\
\hline 14 & 407.48 & 5.41 & -5.51 & -7.90 & 959.10 & 0.14 & 3 & 0.91 & 100 \\
\hline 15 & 469.56 & 5.21 & -4.48 & -6.20 & 713.70 & -0.16 & 7 & 0.82 & 95.57 \\
\hline 16 & 416.49 & 6.73 & -8.63 & -7.49 & 3518.97 & -0.27 & 6 & 1.41 & 100 \\
\hline 17 & 467.58 & 5.18 & -5.38 & -6.81 & 872.36 & -0.13 & 6 & 1.06 & 100 \\
\hline Standard value & $<500$ & $2.0-6.5$ & $>-4$ & $>-5$ & $\begin{array}{l}<25 \text { (poor) } \\
\text { and }>500 \text { (excel- } \\
\text { lent) }\end{array}$ & - & $1-8$ & -1.5 to 1.5 & $0-100 \%$ \\
\hline
\end{tabular}

${ }^{\mathrm{a}} \mathrm{MW}$ : Molecular weight; (Da); ${ }^{\mathrm{b}} \mathrm{Oil} /$ water partition coefficient; ${ }^{\mathrm{c}}$ Solubility; ${ }^{\mathrm{d}} \mathrm{IC}_{50}$ value for blockage of HERG $\mathrm{K}^{+}$channels; ${ }^{\mathrm{e}} \mathrm{Gut}-\mathrm{blood}$ barrier in $\mathrm{nm} / \mathrm{s}$ permeability of the cell model; ${ }^{\mathrm{f}} \mathrm{Brain} / \mathrm{blood}$ partition coefficient; ${ }^{\mathrm{g}}$ Number of metabolic reactions; ${ }^{\mathrm{h}}$ Binding to human serum albumin; ${ }^{\mathrm{i}}$ Human oral absorption. The reference values for ADMET have been taken from the Ref [58] 
Table 4 Analysis of physicochemical properties using Lipinski's rule of Five (Ro5)
Fig. 9 The BOILED-egg model of identified hit molecules (1-17) obtained through SwissADME. BBB and GI permeability have been indicated through yellow and colourless regions, respectively. The blue circles denote inhibition of P-glycoprotein by the corresponding hits

\begin{tabular}{lllllrl}
\hline Compd. No & $\mathrm{MW}^{\mathrm{a}}$ & $\mathrm{HBA}^{\mathrm{b}}$ & $\mathrm{HBD}^{\mathrm{c}}$ & $\operatorname{LogP}^{\mathrm{d}}$ & $\mathrm{RB}^{\mathrm{e}}$ & Violation $^{\mathrm{f}}$ \\
\hline 1 & 453.56 & 5.75 & 1 & 5.18 & 11 & 1 \\
2 & 483.58 & 6.5 & 1 & 5.96 & 12 & 1 \\
3 & 362.49 & 4.5 & 2 & 4.35 & 5 & 0 \\
4 & 449.03 & 5.2 & 2 & 5.06 & 9 & 1 \\
5 & 397.44 & 4.5 & 0 & 5.34 & 4 & 1 \\
6 & 391.37 & 5 & 0 & 4.57 & 2 & 0 \\
7 & 453.56 & 6.25 & 1 & 4.77 & 11 & 0 \\
8 & 373.38 & 5 & 0 & 3.88 & 2 & 0 \\
9 & 414.51 & 6 & 2 & 3.61 & 5 & 0 \\
10 & 451.56 & 6.5 & 1 & 5.43 & 11 & 1 \\
11 & 407.51 & 6.5 & 1 & 4.59 & 8 & 0 \\
12 & 484.04 & 5.75 & 1 & 6.13 & 11 & 1 \\
13 & 470.01 & 5.75 & 0 & 5.63 & 10 & 1 \\
14 & 407.48 & 4.45 & 2 & 5.41 & 8 & 1 \\
15 & 469.56 & 6.5 & 1 & 5.21 & 11 & 1 \\
16 & 416.49 & 3.25 & 2 & 6.73 & 6 & 1 \\
17 & 484.04 & 5.75 & 1 & 6.13 & 11 & 1 \\
Standard value & $<500$ & $<10$ & $<5$ & $<5$ & $<5$ & - \\
\hline
\end{tabular}

${ }^{\mathrm{a}}$ Molecular weight (Da), ${ }^{\mathrm{b}}$ Number of hydrogen bond acceptors, ${ }^{\mathrm{c}}$ Number of hydrogen bond donors, ${ }^{\mathrm{d}}$ Partition coefficient in oil to water, ${ }^{\mathrm{e}} \mathrm{Number}$ of rotational bonds, ${ }^{\mathrm{f}} \mathrm{Number}$ of violated parameters from Ro5

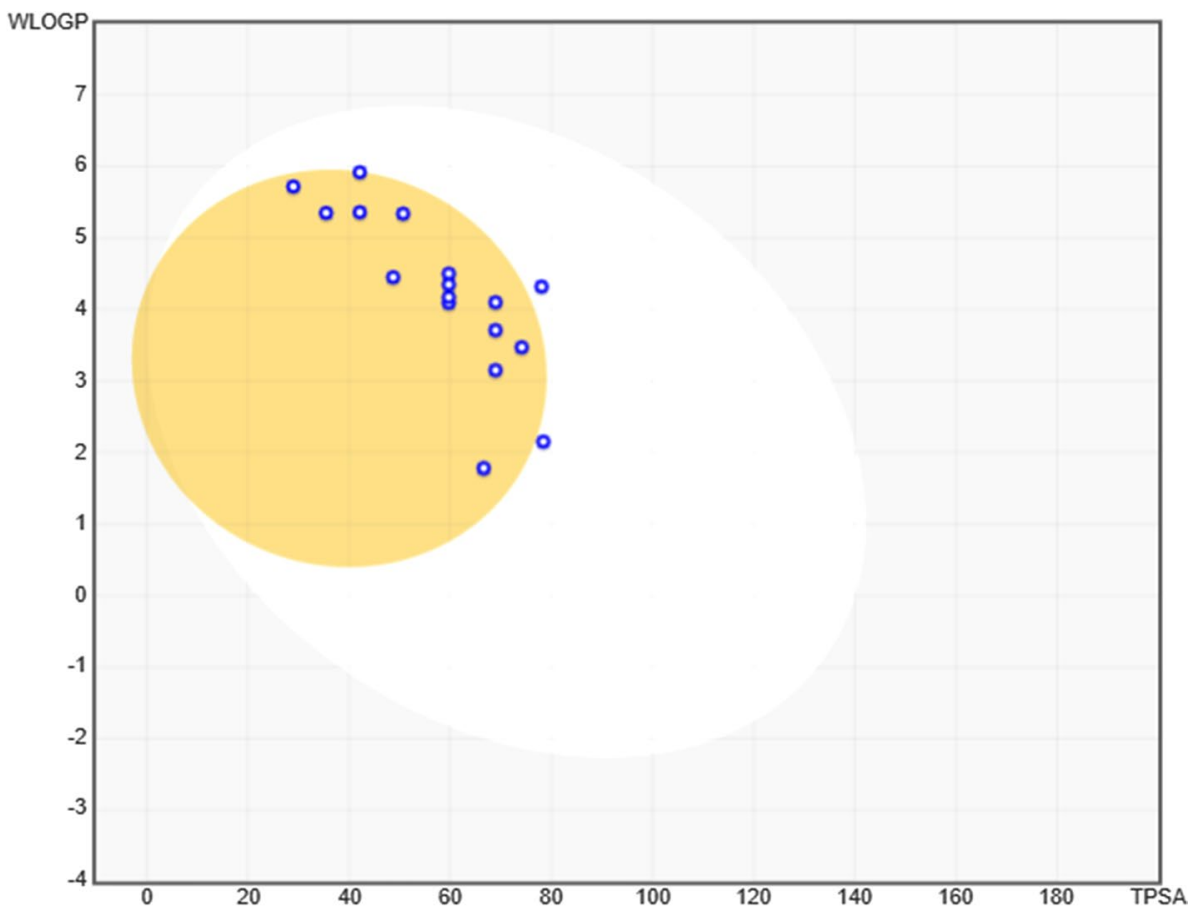

degradation of these peptides under the acidic environment of stomach and peptidase enzymes [64].

\section{MD simulation}

Molecular dynamics simulations have been recognized as significant tool to claim the stability of the ligand and to reveal macromolecular structure to function relationships in the field of drug discovery [65-68]. Henceforth, 
we performed the molecular dynamics (MD) simulations at various time points up to $10 \mathrm{~ns}$ using GROMACS 2020.1 to assess the stability of the hits into the complexes obtained from ADMET and Lipinski rules analysis [69, 70]. The graphical representation of plots of statistical parameters obtained by the MD simulation of compound 1 is presented in Fig. 10. The ligand-receptor complex of 1 with spike was found with root mean square deviation (RMSD) value ranging from 5.81 to $10.14 \mathrm{~nm}$ with an average of $8.889 \mathrm{~nm}$ (Fig. 10a) for the ligand and $7.06-10.14 \mathrm{~nm}$ with an average of $9.710 \mathrm{~nm}$ (Fig. 10b) for the protein. Although these values were little high, the stability of the ligand into the active site was found consistent as evident from Fig. 10a, b. The radius of gyration (RoG) for the same complex ranging from 7.13 to $8.90 \mathrm{~nm}$ with an average of $8.311 \mathrm{~nm}$ (Fig. 10c) indicated the compactness of the complex. The surface area accessed by the solvent molecules was found within the range from 1550 to $1590 \mathrm{~nm}^{2}$ with an average of $1586.597 \mathrm{~nm}^{2}$ (Fig. 10d). The plot of number of hydrogen bonds (HB) vs simulation time revealed maximum five $\mathrm{HBs}$ between the ligand and receptor within the time period of $10 \mathrm{~ns}$ (Fig. 10e). The electrostatic (coulombic short-range, Coul-SR) and van der Waals/hydrophobic interactions (LJ-SR) for the complex were found $-230.361 \pm 7.5$ and $-146.553 \pm 5 \mathrm{~kJ} /$ mol, respectively, which indicated the key role of the
Fig. 10 The schematic plots of (6a) RMSD-L, (6b) RMSD-P, (6c) RoG, (6d) SASA and (6e) $\mathrm{HB}$ for the complex of compound $\mathbf{1}$ with spike glycoprotein
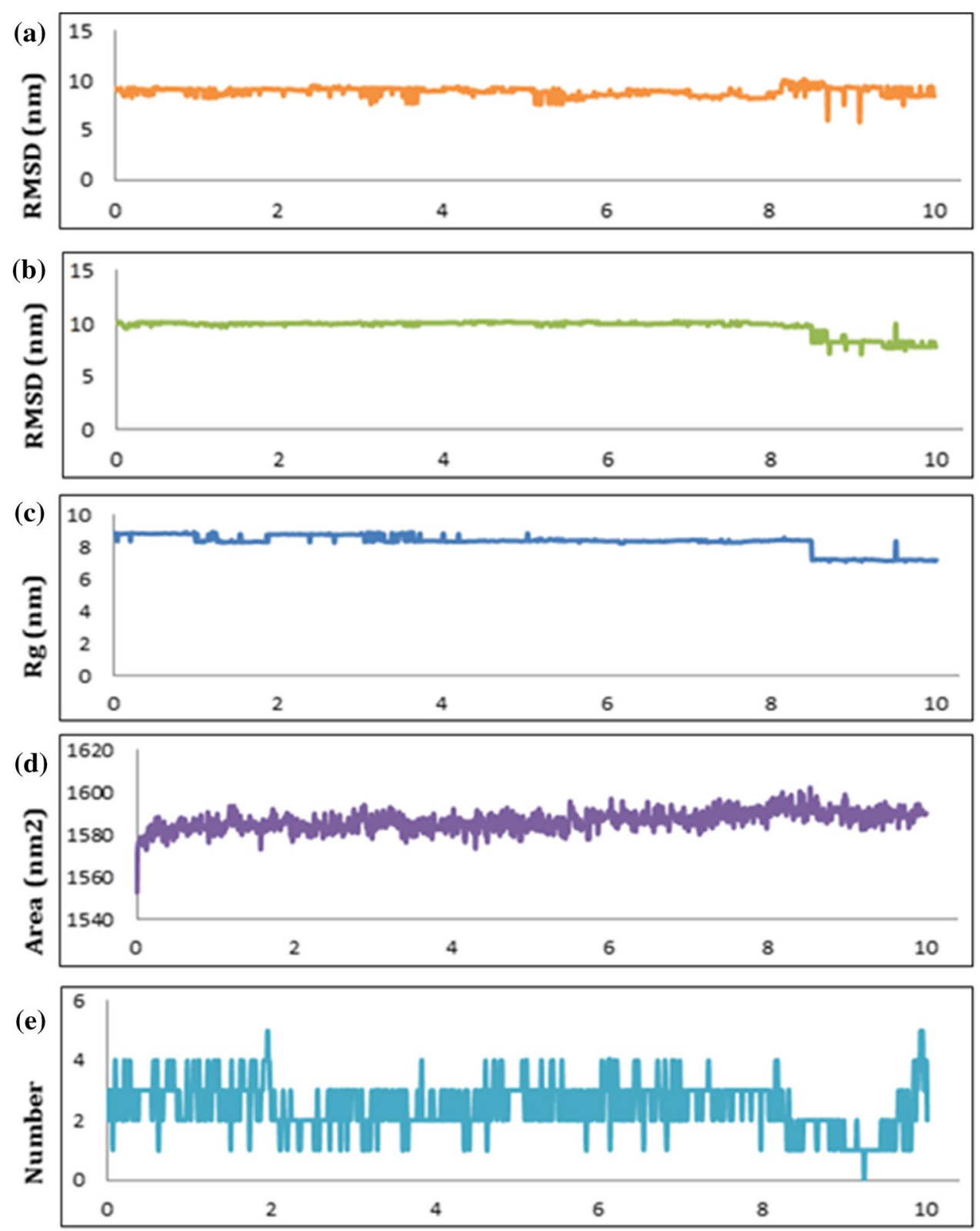

Time (ns) 
electrostatic interactions to stabilize the complex of $\mathbf{1}$ with spike glycoprotein.

The graphical representation of plots of statistical parameters obtained by the MD simulation of compound $\mathbf{2}$ is represented in Fig. 11. The ligand-receptor complex of $\mathbf{2}$ with the spike glycoprotein was found with RMSD value ranging from 7.08 to $11.32 \mathrm{~nm}$ with an average of $9.05 \mathrm{~nm}$ (Fig. 11a) for the ligand and 7.39-7.80 nm with an average of $7.70 \mathrm{~nm}$ (Fig. 11b) for the protein. Although these values were high, the stability of the ligand into the active site was found consistent during 0-8 ns, and little instability was observed after $8 \mathrm{~ns}$ in the RMSD. The radius of gyration (RoG) for the same complex ranging from 8.4 to $8.8 \mathrm{~nm}$ with an average of $8.586 \mathrm{~nm}$ (Fig. 11c) indicated the compactness of the complex. The surface area accessed by the solvent molecules was found within the range from 1030 to $1070 \mathrm{~nm}^{2}$ with an average of $1060.85 \mathrm{~nm}^{2}$ (Fig. 11d). The plot of number of hydrogen bonds (HB) vs simulation time revealed maximum four HBs between the ligand and receptor within the time period of $10 \mathrm{~ns}$ (Fig. 11e). The electrostatic (coulombic short-range, Coul-SR) and van der Waals/hydrophobic interactions (LJ-SR) for the complex were found $-87.9052 \pm 18$ and $-72.2626 \pm 13 \mathrm{~kJ} / \mathrm{mol}$, respectively.

\section{Conclusions}

In the search of effective SARS CoV-2 inhibitors inhibiting the viral entry of coronavirus into host cells, the systematic virtual screening of ligands from Asinex BioDesign library
Fig. 11 The schematic plots of (7a) RMSD-L, (7b) RMSD-P, (7c) RoG, (7d) SASA and (7e) HB for the complex of compound $\mathbf{2}$ with spike glycoprotein
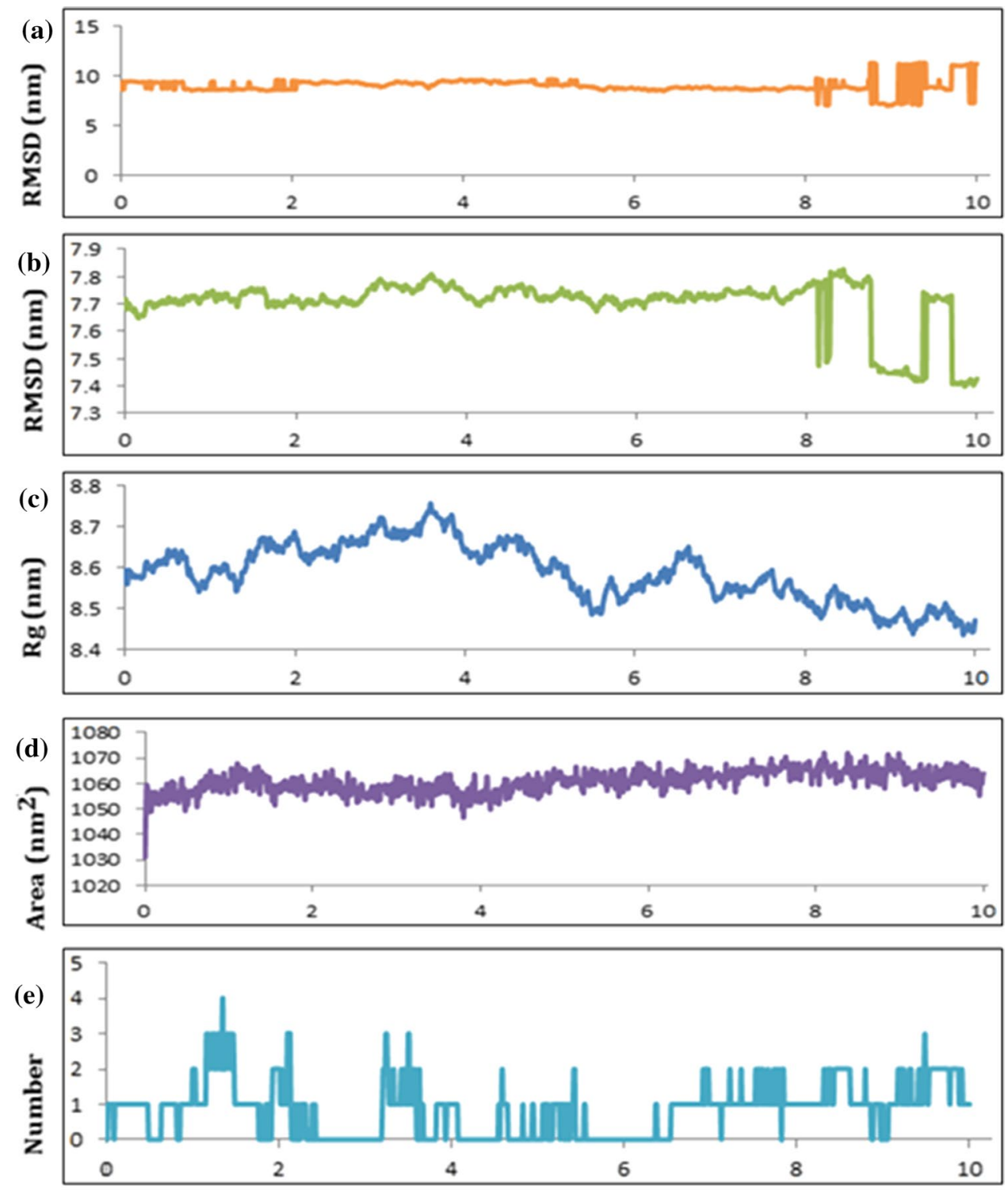

Time (ns) 
2020.1 has been performed against spike glycoprotein, a promising target of SARS CoV-2. The predicted binding site of spike glycoprotein has been used for pharmacophorebased screening, wherein the selected ligands with essential pharmacophoric features have been subjected for three different levels of precise molecular docking to shortlist the identified hits with the desired docking score. Total seventeen hits having the promising docking score have qualified the ADMET parameters and Lipinski's rule of five properties to claim their oral bioavailability. The dynamics simulation studies have demonstrated the stability of identified hits (1 and $\mathbf{2}$ ) into the predicted catalytic site of protein with sufficient compactness, uniqueness and stability. In summary, the present studies accomplishes that the identified hits may interfere with the key residues of spike glycoprotein effectively as SARS CoV-2 inhibitors with sufficient binding affinity, good stability into the active site with the acceptable drug likeliness. These studies have provided SARS CoV-2 inhibitors having the potential of inhibiting the viral entry into the host cell by acting on the viral spike protein against COVID-19.

\section{Computational details}

\section{Preparation of ligands}

Asinex BioDesign library 2020.1, comprising of 175,851 molecules with pharmacologically important structural features in the chemical scaffolds with synthetic feasibility, has been accessed through open source databases [39]. The ligands were prepared for molecular modelling using LigPrep, where the possible states of ionization were generated using Epik at physiological $\mathrm{pH}(7.0 \pm 2.0)$ with consideration of metal binding states, removal of salt forms and generation of tautomeric isomers or stereoisomers using the OPLS3e force field [40].

\section{Preparation of proteins}

The 3D structure of SARS CoV-2 spike glycoprotein (PDB ID: 6VXX) having resolution of $2.8 \AA$ has been accessed from RCSB protein data bank [71]. The protein has been modified using protein preparation wizard (PrepWizard) of Schrödinger suite (Maestro 12.5) [72]. The hydrogen consistency, steric relations, bond orders and total charges have been generated followed by optimization and energy minimization of protein using the force field (OPLS3e) to assure the structural accuracy of final protein.

\section{Site map analysis}

The selected protein does not contain any co-crystallized ligand or inhibitor. In a view of this, the site map analysis has been performed to identify specific receptor binding site [36]. The possible binding site regions with minimum fifteen site points have been generated under more restrictive hydrophobic environment using standard grid to visualize and evaluate the top-most binding sites. For further molecular modelling, binding site with the highest drugability score (DScore) has been selected as an active site from the nominated top five binding sites.

\section{Pharmacophore development and screening}

The selected protein of interest (PDB ID: 6VXX) does not contain any co-crystallized ligand [35]. The residues have been specified through the atom specification language (ASL) for the selected best active site with highest D score followed by the generation of receptor cavity-based E-pharmacophore hypothesis using the phase module of Schrödinger [38]. The model has been generated for the selected active site along with the generation of seven features (RRRRRRH), comprising of aromatic ring (R) and hydrophobic feature $(\mathrm{H})$. The molecules prepared after the LigPrep have been subjected to phase ligand screening to fit with minimum four of the identified features of the generated pharmacophore hypothesis model. Maximum fifty conformers for each ligand have been generated and subjected to energy minimization. The phase screen score for each conformer has been calculated based on preset acceptor and donor as negative and positive equivalent, respectively. Total 38,267 molecules have qualified with the set features of hypothesis from the selected drug library.

\section{Molecular docking}

\section{Receptor grid generation}

The grid box of size $10 \AA$ has been generated using GLIDE module of Schrödinger on the identified binding site from site map analysis with the highest DScore [53]. The van der Waals radius scaling factor and the partial charge cut-off have been set 1 and 0.25 , respectively, to soften the potential for nonpolar parts of the protein.

\section{Ligand docking}

Next, molecular docking has been performed using GLIDE module of Schrödinger. The 38,267 ligands which have qualified through the phase screening, have been docked on selected active sites of the protein using high throughput virtual screening (HTVS) through flexible ligand sampling and one pose per each ligand has been generated. A total of 1094 molecules with docking score of $\leq-4.6$ obtained in HTVS docking have been further docked on the same active site using standard precision (SP) to generate one pose 
for each ligand. Again 175 top compounds having docking score $\leq-5.9$ have been further docked with extra precision (XP) to generate 10 poses per ligand. ADMET analysis with Lipinski parameters has been performed for 17 hits having docking score of $\leq-6.0$ in XP docking. The interactions of the ligand with the amino acids of the active site have been visualized using PyMol 2.4.1 [54].

\section{ADMET analysis and Lipinski rule of five}

The absorption, distribution, metabolism, excretion and toxicity (ADMET) analysis and assessment of Lipinski parameters have been carried out using QikProp module of Schrödinger for the obtained 16 hits which have achieved the docking score less than -6.33 in XP docking [57]. The various physical, chemical and functional group properties such as molecular weight, oil/water partition coefficient, solubility, $\mathrm{IC}_{50}$ value for blockage of HERG $\mathrm{K}^{+}$channels, gut-blood barrier in $\mathrm{nm} / \mathrm{s}$ permeability of the cell model, brain/blood partition coefficient, number of metabolic reactions, binding to human serum albumin and human oral absorption have been studied from the manual analysis of the result of ADMET analysis. The drug likeliness features like molecular weight, hydrogen bond donors, hydrogen bond acceptors, partition coefficient (oil/water) and number of rotatable bonds have been studied through Lipinski rule of five.

\section{Molecular dynamics (MD) simulation}

Hit molecule obtained from the manual analysis of ADMET and Lipinski parameters have been incorporated to perform the MD simulation using GROningen MAchine for Chemical Simulations (GROMACS) $2020.1[69,70]$ software. CHARMM36 (Chemistry at Harvard Macromolecular Mechanics) was used as an all atom force field [73] and CHARMM General Force Field (CGenFF) server [74, 75] was used to generate the topology of the ligands. After solvation (TIP3P water model) and neutralization (sodium chloride), the complex was subjected to energy minimization followed by equilibration through the canonical isovolumetric-isothermal (NVT) and isobaric-isothermic (NPT) canonicals for $100 \mathrm{ps}$. The energy minimized complexes have been subjected for final MD run of $10 \mathrm{~ns}$ for successful completion.

Supplementary Information The online version contains supplementary material available at https://doi.org/10.1007/s11030-022-10394-9.

Acknowledgements The authors would like to acknowledge the support provided by Schrödinger Inc. for performing molecular modelling under the banner of Drug Discovery Hackathon 2020 (DDH-2020), a joint initiative of All India Council of Technical Education (AICTE),
New Delhi, Council of Scientific and Industrial Research (CSIR), New Delhi, and Government of India.

Author contributions All the authors contributed equally for this work. TMD performed docking, data generation, conceptualization, supervision, writing - original draft and revised manuscript preparation, and reviewing and editing; PRN contributed to methodology, data generation, docking, writing — original draft and revised manuscript preparation; and NDG contributed to methodology, data generation, docking, ADMET assay, MD simulations, writing—original draft and revised manuscript preparation.

\section{References}

1. Hu B, Guo H, Zhou P, Shi ZL (2020) Characteristics of SARSCoV-2 and COVID-19. Nat Rev Microbiol 19:141-154. https:// doi.org/10.1038/s41579-020-00459-7

2. Cui J, Li F, Shi ZL (2019) Origin and evolution of pathogenic coronaviruses. Nat Rev Microbiol 17:181-192. https://doi.org/10. 1038/s41579-018-0118-9

3. Ashour HM, Elkhatib WF, Rahman MM, Elshabrawy HA (2020) Insights into the recent 2019 novel coronavirus (SARS-CoV-2) in light of past human coronavirus outbreaks. Pathogens 9:e186. https://doi.org/10.3390/pathogens9030186

4. Pillaiyar T, Wendt LL, Manickam M, Easwaran M (2021) The recent outbreaks of human coronaviruses: a medicinal chemistry perspective. Med Res Rev 41:72-135. https://doi.org/10.1002/ med.21724

5. Wu JT, Leung K, Leung GM (2020) Nowcasting and forecasting the potential domestic and international spread of the 2019-nCoV outbreak originating in Wuhan, China: a modeling study. Obstet Gynecol Surv 75:399-400. https://doi.org/10.1097/01.ogx.00006 88032.41075.a8

6. Hui DS, Azhar EI, Madani TA et al (2020) The continuing 2019$\mathrm{nCoV}$ epidemic threat of novel coronaviruses to global health: the latest 2019 novel coronavirus outbreak in Wuhan, China. Int J Infect Dis 91:264-266. https://doi.org/10.1016/j.ijid.2020.01.009

7. World Health Organization. (2020) Coronavirus disease 2019 (COVID-19). Situation report: 51. https://www.who.int/docs/ default-source/coronaviruse/situation-reports/20200311-sitrep51-covid-19.pdf?sfvrsn=1ba62e57_10. Accessed 2 Feb 2021

8. WHO Coronavirus Disease (COVID-19) Dashboard. https://covid 19.who.int/. Accessed 18 Jan 2022

9. Nicola M, Alsafi Z, Sohrabi C et al (2020) The socio-economic implications of the coronavirus pandemic (COVID-19): a review. Int J Surg 78:185-193. https://doi.org/10.1016/j.ijsu.2020.04.018

10. Bashir MF, Ma B, Shahzad L (2020) A brief review of socio-economic and environmental impact of COVID-19. Air Qual Atmos Heal 13:1403-1409. https://doi.org/10.1007/s11869-020-00894-8

11. Mousavizadeh L, Ghasemi S (2020) Genotype and phenotype of COVID-19: their roles in pathogenesis. J Microbiol Immunol Infect 54:159-163. https://doi.org/10.1016/j.jmii.2020.03.022

12. Ahidjo BA, Loe MWC, Ng YL et al (2020) Current perspective of antiviral strategies against COVID-19. ACS Infect Dis 6:16241634. https://doi.org/10.1021/acsinfecdis.0c00236

13. Tyrrell DAJ, Myint SH (1996) Coronaviruses. In: Baron S (ed) Medical Microbiology. University of Texas Medical Branch at Galveston, Galveston

14. Zhu N, Zhang D, Wang W et al (2020) A novel coronavirus from patients with pneumonia in China, 2019. N Engl J Med 382:727733. https://doi.org/10.1056/nejmoa2001017 
15. Freitas BT, Durie IA, Murray J et al (2020) Characterization and noncovalent inhibition of the deubiquitinase and deISGylase activity of SARS-CoV-2 papain-like protease. ACS Infect Dis 6:2099-2109. https://doi.org/10.1021/acsinfecdis.0c00168

16. Lu R, Zhao X, Li J et al (2020) Genomic characterisation and epidemiology of 2019 novel coronavirus: implications for virus origins and receptor binding. Lancet 395:565-574. https://doi.org/ 10.1016/S0140-6736(20)30251-8

17. Woo PCY, Lau SKP, Huang Y, Yuen KY (2009) Coronavirus diversity, phylogeny and interspecies jumping. Exp Biol Med 234:1117-1127. https://doi.org/10.3181/0903-MR-94

18. Guan W, Ni Z, Hu Y et al (2020) Clinical characteristics of coronavirus disease 2019 in China. N Engl J Med 382:1708-1720. https://doi.org/10.1056/nejmoa2002032

19. Rothan HA, Byrareddy SN (2020) The epidemiology and pathogenesis of coronavirus disease (COVID-19) outbreak. J Autoimmun 109:102433. https://doi.org/10.1016/j.jaut.2020.102433

20. Singhal T (2020) A review of coronavirus disease-2019 (COVID19). Indian J Pediatr 87:281-286. https://doi.org/10.1007/ s12098-020-03263-6

21. Ghosh AK, Brindisi M, Shahabi D et al (2020) Drug development and medicinal chemistry efforts toward SARS-coronavirus and COVID-19 therapeutics. ChemMedChem 15:907-932. https://doi. org/10.1002/cmdc.202000223

22. Mohamed K, Yazdanpanah N, Saghazadeh A, Rezaei N (2021) Computational drug discovery and repurposing for the treatment of COVID-19: a systematic review. Bioorg Chem 106:104490. https://doi.org/10.1016/j.bioorg.2020.104490

23. Wang X, Guan Y (2021) COVID-19 drug repurposing: A review of computational screening methods, clinical trials, and protein interaction assays. Med Res Rev 41:5-28. https://doi.org/10.1002/ med. 21728

24. Chakravarti R, Singh R, Ghosh A et al (2021) A review on potential of natural products in the management of COVID-19. RSC Adv 11:16711-16735. https://doi.org/10.1039/d1ra00644d

25. Shagufta AI (2021) The race to treat COVID-19: Potential therapeutic agents for the prevention and treatment of SARS-CoV-2. Eur J Med Chem 213:113157. https://doi.org/10.1016/j.ejmech. 2021.113157

26. Tang T, Bidon M, Jaimes JA et al (2020) Coronavirus membrane fusion mechanism offers a potential target for antiviral development. Antiviral Res 178:104792. https://doi.org/10.1016/j.antiv iral.2020.104792

27. Varghese PM, Tsolaki AG, Yasmin H et al (2020) Host-pathogen interaction in COVID-19: pathogenesis, potential therapeutics and vaccination strategies. Immunobiology 225:152008. https://doi. org/10.1016/j.imbio.2020.152008

28. Bojadzic D, Alcazar O, Chen J et al (2021) Small-molecule inhibitors of the coronavirus spike: ACE2 protein-protein interaction as blockers of viral attachment and entry for SARS-CoV-2. ACS Infect Dis 7:1519-1534. https://doi.org/10.1021/acsinfecdis.1c000 70

29. Day CJ, Bailly B, Guillon P et al (2021) Multidisciplinary approaches identify compounds that bind to human ACE2 or SARS-CoV-2 spike protein as candidates to block SARS-CoV-2ACE2 receptor interactions. MBio 12:e03681-e3720. https://doi. org/10.1128/mBio.03681-20

30. Freitas FC, Ferreira PHB, Favaro DC, De ORJ (2021) Shedding light on the inhibitory mechanisms of SARS-CoV-1/CoV-2 spike proteins by ACE2-designed peptides. J Chem Inf Model 61:12261243. https://doi.org/10.1021/acs.jcim.0c01320

31. Rajpoot S, Ohishi T, Kumar A et al (2021) A novel therapeutic peptide blocks SARS-CoV-2 spike protein binding with host cell ACE2 receptor. Drugs R D 21:273-283. https://doi.org/10.1007/ s40268-021-00357-0
32. Bharatam PV (2021) Computer-aided drug design. In: Poduri R (ed) Drug discovery and development. Springer, Singapore, pp 137-210

33. Nagar PR, Gajjar ND, Dhameliya TM (2021) In search of SARS CoV-2 replication inhibitors: virtual screening, molecular dynamics simulations and ADMET analysis. J Mol Struct 1246:131190. https://doi.org/10.1016/j.molstruc.2021.131190

34. Gajjar ND, Dhameliya TM, Shah GB (2021) In search of RdRp and Mpro inhibitors against SARS CoV-2: molecular docking, molecular dynamic simulations and ADMET analysis. J Mol Struct 1239:130488. https://doi.org/10.1016/j.molstruc.2021. 130488

35. Walls AC, Park YJ, Tortorici MA et al (2020) Structure, function, and antigenicity of the SARS-CoV-2 spike glycoprotein. Cell 181:281-292.e6. https://doi.org/10.1016/j.cell.2020.02.058

36. Schrödinger Release 2020-3: SiteMap, Schrödinger, LLC, New York, NY, 2020

37. Vidler LR, Brown N, Knapp S, Hoelder S (2012) Druggability analysis and structural classification of bromodomain acetyllysine binding sites. J Med Chem 55:7346-7359. https://doi.org/ $10.1021 / \mathrm{jm} 300346 \mathrm{w}$

38. Schrödinger Release 2020-3: Phase, Schrödinger, LLC, New York, NY, 2020

39. Asinex. http://www.asinex.com/. Accessed 17 Aug 2019

40. Schrödinger Release 2020-3: LigPrep, Schrödinger, LLC, New York, NY, 2020

41. Dhameliya TM, Tiwari R, Banerjee A et al (2018) Benzo[d]thiazole-2-carbanilides as new anti-TB chemotypes: design, synthesis, biological evaluation, and structure-activity relationship. Eur J Med Chem 155:364-380. https://doi.org/10.1016/j.ejmech.2018. 05.049

42. Jadhavar PS, Dhameliya TM, Vaja MD et al (2016) Synthesis, biological evaluation and structure-activity relationship of 2-styrylquinazolones as anti-tubercular agents. Bioorg Med Chem Lett 26:2663-2669. https://doi.org/10.1016/j.bmcl.2016.04.012

43. Shah P, Dhameliya TM, Bansal R et al (2014) $N$-Arylalkylbenzo $[d]$ thiazole-2-carboxamides as anti-mycobacterial agents: design, new methods of synthesis and biological evaluation. Med Chem Commun 5:1489-1495. https://doi.org/10.1039/C4MD00224E

44. Bhakhar KA, Gajjar ND, Bodiwala KB et al (2021) Identification of anti-mycobacterial agents against mmpL3: virtual screening, ADMET analysis and MD simulations. J Mol Struct 1244:130941. https://doi.org/10.1016/j.molstruc.2021.130941

45. Alexpandi R, De Mesquita JF, Pandian SK, Ravi AV (2020) Quinolines-based SARS-CoV-2 3CLpro and RdRp inhibitors and Spike-RBD-ACE2 inhibitor for drug-repurposing against COVID19: an in silico analysis. Front Microbiol. https://doi.org/10.3389/ fmicb.2020.01796

46. Ferraz WR, Gomes RA, Novaes ALS, Goulart Trossini GH (2020) Ligand and structure-based virtual screening applied to the SARSCoV-2 main protease: an in silico repurposing study. Future Med Chem 12:1815-1828. https://doi.org/10.4155/fmc-2020-0165

47. Shahinshavali S, Hossain KA, Kumar AVDN et al (2020) Ultrasound assisted synthesis of 3-alkynyl substituted 2-chloroquinoxaline derivatives: their in silico assessment as potential ligands for $N$-protein of SARS-CoV-2. Tetrahedron Lett 61:152336. https:// doi.org/10.1016/j.tetlet.2020.152336

48. Olubiy OO, Olagunju M, Keutmann M et al (2020) High throughput virtual screening to discover inhibitors of the main protease of the coronavirus SARS-CoV-2. Molecules 25:3193. https://doi. org/10.3390/molecules 25143193

49. Ngo ST, Quynh Anh Pham N, Le Thi L et al (2020) Computational determination of potential inhibitors of SARS-CoV-2 main protease. J Chem Inf Model 60:5771-5780. https://doi.org/10. 1021/acs.jcim.0c00491 
50. Hagar M, Ahmed HA, Aljohani G, Alhaddad OA (2020) Investigation of some antiviral N-heterocycles as COVID 19 drug: molecular docking and DFT calculations. Int J Mol Sci 21:3922. https://doi.org/10.3390/ijms21113922

51. Gentile D, Patamia V, Scala A et al (2020) Putative inhibitors of SARS-COV-2 main protease from a library of marine natural products: a virtual screening and molecular modeling study. Mar Drugs 18:225. https://doi.org/10.3390/md18040225

52. Chemboli R, Kapavarapu R, Deepti K et al (2021) Pyrrolo[2,3-b] quinoxalines in attenuating cytokine storm in COVID-19: their sonochemical synthesis and in silico/in vitro assessment. J Mol Struct 1230:129868. https://doi.org/10.1016/j.molstruc. 2020. 129868

53. Schrödinger Release 2020-3: Glide, Schrödinger, LLC, New York, NY, 2020

54. DeLano WL (2002). The PyMOL molecular genetics graphics system, DeLano Scientific LLC, San Carlos

55. Dhameliya TM, Chudasma SJ, Patel TM, Dave BP (2022) A review on synthetic account of 1,2,4-oxadiazoles as anti-infective agents. Mol Divers. https://doi.org/10.1007/s11030-021-10375-4

56. Bhakhar KA, Sureja DK, Dhameliya TM (2022) Synthetic account of indoles in search of potential anti-mycobacterial agents: a review and future insights. J Mol Struct 1248:131522. https:// doi.org/10.1016/j.molstruc.2021.131522

57. Schrödinger Release 2020-3: QikProp, Schrödinger, LLC, New York, NY, 2020

58. Modi P, Patel S, Chhabria M (2019) Structure-based design, synthesis and biological evaluation of a newer series of pyrazolo[1,5a]pyrimidine analogues as potential anti-tubercular agents. Bioorg Chem 87:240-251. https://doi.org/10.1016/j.bioorg.2019.02.044

59. Lipinski CA, Lombardo F, Dominy BW, Feeney PJ (2001) Experimental and computational approaches to estimate solubility and permeability in drug discovery and devlopment settings. Adv Drug Deliv Rev 46:3-26. https://doi.org/10.1016/s0169-409x(00) 00129-0

60. Daina A, Zoete V (2016) A BOILED-Egg to predict gastrointestinal absorption and brain penetration of small molecules. ChemMedChem 11:1117-1121. https://doi.org/10.1002/cmdc. 201600182

61. Daina A, Michielin O, Zoete V (2017) SwissADME: a free web tool to evaluate pharmacokinetics, drug-likeness and medicinal chemistry friendliness of small molecules. Sci Reports 7:42717. https://doi.org/10.1038/srep42717

62. Levine WG (1991) Metabolism of aZO dyes: implication for detoxication and activation. Drug Metab Rev 23:253-309. https:// doi.org/10.3109/03602539109029761
63. Purohit V, Basu AK (2000) Mutagenicity of nitroaromatic compounds. Chem Res Toxicol 13:673-692. https://doi.org/10.1021/ tx000002x

64. Sewald N, Jakubke H-D (2009) Peptides: chemistry and biology, 2nd edn. Wiley-VCH, New York

65. Naqvi AAT, Mohammad T, Hasan GM, Hassan MI (2019) Advancements in docking and molecular dynamics simulations towards ligand-receptor interactions and structure-function relationships. Curr Top Med Chem 18:1755-1768. https://doi.org/10. 2174/1568026618666181025114157

66. Salo-Ahen OMH, Alanko I, Bhadane R et al (2021) Molecular dynamics simulations in drug discovery and pharmaceutical development. Processes 9:71. https://doi.org/10.3390/pr9010071

67. Bera I, Payghan PV (2019) Use of molecular dynamics simulations in structure-based drug discovery. Curr Pharm Des 25:33393349. https://doi.org/10.1021/acs.jpcb.1c04556

68. Padhi AK, Rath SL, Tripathi T (2021) Accelerating COVID-19 research using molecular dynamics simulation. J Phys Chem B 125:9078-9091. https://doi.org/10.1021/acs.jpcb.1c04556

69. Abraham MJ, Berk Hess, Lindahl E, Spoel D van der (2020) GROMACS 2020.1 (Manual Version 2020.1) Zenodo. https:// doi.org/10.5281/zenodo.4054996. Accessed 10 Sep 2020

70. Abraham MJ, Murtola T, Schulz R et al (2015) GROMACS: High performance molecular simulations through multi-level parallelism from laptops to supercomputers. SoftwareX 1-2:19-25

71. Protein Data Bank. https://www.rcsb.org/. Accessed 30 Aug 2020

72. Protein Preparation Wizard; Epik, Schrödinger, LLC, New York, NY, (2020) Impact, Schrödinger, LLC, New York, NY, 2020; Prime, Schrödinger, LLC, New York, NY, 2020

73. Huang J, Rauscher S, Nawrocki G et al (2016) CHARMM36m: an improved force field for folded and intrinsically disordered proteins. Nat Methods 14:71-73. https://doi.org/10.1038/nmeth. 4067

74. Vanommeslaeghe K, Hatcher E, Acharya C et al (2010) CHARMM general force field: a force field for drug-like molecules compatible with the CHARMM all-atom additive biological force fields. J Comput Chem 31:671-690. https://doi.org/10. $1002 / j c c .21367$

75. Yu W, He X, Vanommeslaeghe K, MacKerell AD (2012) Extension of the CHARMM general force field to sulfonyl-containing compounds and its utility in biomolecular simulations. J Comput Chem 33:2451-2468. https://doi.org/10.1002/jcc.23067

Publisher's Note Springer Nature remains neutral with regard to jurisdictional claims in published maps and institutional affiliations. 